\title{
ON THE OPEN BALL CENTERED AT AN INVERTIBLE ELEMENT OF A BANACH ALGEBRA
}

\author{
Sebastian Geethika and Daniel SuKumar
}

Abstract. Let $A$ be a complex unital Banach algebra. Since the set of invertible elements is open, there is an open ball around every invertible element. In this article, we investigate the Banach algebras for which the radius given by the Neumann series is optimal.

Mathematics subject classification (2010): Primary 46H05, secondary 46H20.

Keywords and phrases: Invertible elements, spectrum, norm attaining, semi simple.

\section{REFERENCES}

[1] G. R. Allan and H. G. Dales, Introduction to Banach Spaces and Algebras, Oxford University Press, 2011.

[2] F. F. Bons all and J. Duncan, Complete normed algebras, Springer-Verlag, 1973.

[3] A. Deitmar and S. Echterhoff, Principles of Harmonic Analysis, Springer International Publishing, 2014.

[4] J. L. KeLLEY, General Topology, Springer, New York, 1975.

[5] G. KRishna Kumar And S. H. KUlKaRni, An analogue of the spectral mapping theorem for condition spectrum, Oper. Theory Adv. Appl. 236, 299-316, 2014.

[6] ARUNDATHI KRISHNAN AND S. H. KULKARNi, Pseudospectrum of an element of a Banach algebra, Oper. Matrices 11 (1), 263-287, 2017.

[7] S. H. Kulkarni, And D. Sukumar, The condition spectrum, Acta Sci. Math. (Szeged) 74 (3-4), 625-641, 2008.

[8] S. H. KUlKarni, AND D. SUKUmar, Almost multiplicative functions on commutative Banach algebras, Studia Math. 197 (1), 93-99, 2010.

[9] C. R. Putnam, Operators satisfying a $G_{1}$ condition, Pacific J. Math. 84 (2), 413-426, 1979.

[10] S. SHKARIN, Norm attaining operators and pseudospectrum, Integral Equations Operator Theory 64 (1), 115-136, 2009. 